\title{
Distinctiveness in serial memory for spatial information
}

\author{
KATHERINE GUÉRARD \\ Université Laval, Québec, Québec, Canada \\ Ian Neath ANd Aimée M. Surprenant \\ Memorial University of Newfoundland, St. John's, Newfoundland, Canada
}

AND

SÉbastien TRemblaY

Université Laval, Québec, Québec, Canada

\begin{abstract}
Several studies have shown that recall performance depends on the extent to which an item differs from other items in a sequence (the distinctiveness effect; see, e.g., Kelley \& Nairne, 2001). Distinctiveness effects, however, have been demonstrated mainly in the verbal domain. The present study extends distinctiveness effects to the spatial domain. In two experiments, participants recalled the order in which series of spatially located dots had been presented. Item discriminability was varied within the sequence by manipulating the duration of the interval inserted between the presentation of the dots (Experiment 1) and the perceptual characteristics of the stimuli (Experiment 2). The results showed that these manipulations in the spatial domain produce distinctiveness effects similar to those observed with verbal material (see, e.g., Neath \& Crowder, 1990) and suggest that distinctiveness models of memory should take into account the processing of spatial information.
\end{abstract}

Many theories of memory are based on the concept of distinctiveness, the idea that an item will be well remembered if it "stands out" from other items at the time of retrieval. Beginning with Murdock (1960), a number of mathematical and simulation models of distinctiveness have been developed (for a review, see Neath \& Brown, 2007). Most recent work has focused on making one verbal item differ from others in the list, by changing its color (e.g., Bireta, Surprenant, \& Neath, 2008; Huang \& Wille, 1979), its size (Kelley \& Nairne, 2001; Kroll, 1972), or its semantic category (e.g., Geraci, McDaniel, Manzano, \& Roediger, 2009). A related line of work also uses verbal stimuli but manipulates the temporal distinctiveness of the items over the whole list (e.g., Brown, Morin, \& Lewandowsky, 2006; Neath \& Crowder, 1990). Most distinctiveness effects have been shown using verbal material, and, therefore, it is not clear whether typical distinctiveness effects apply to the processing of spatial information and, if they do, whether the results are consistent with the various distinctiveness models. Moreover, in most studies reporting perceptual distinctiveness effects, recall performance has been examined for a single isolated item in a to-be-remembered list (see, e.g., Huang \& Wille, 1979; Kelley \& Nairne, 2001; Kroll, 1972). Consequently, it is difficult to know whether the principles responsible for distinctiveness effects apply to a whole list or are specific to the processing of a single isolated item. The objective of the present series of experiments, then, was to examine whether item discriminability influences memory for spatial information over the whole serial position curve, whether it is manipulated over a temporal or a perceptual dimension.

Several studies have produced distinctiveness effects by manipulating the temporal characteristics of a sequence. The typical procedure consists of varying the duration of the intervals of time inserted between the presentation of two successive items throughout a list (e.g., Lewandowsky, Brown, Wright, \& Nimmo, 2006; Neath \& Crowder, 1990, 1996; Welte \& Laughery, 1971). Neath and Crowder (1990) used different schedules of presentation in which the interstimulus interval (ISI) increased from short intervals to long intervals or decreased from long intervals to short intervals as the words in the list were presented. Such a manipulation influences item discriminability throughout the whole list. For example, in the increasing condition, in which the duration of the ISI increases across list items, the first items of the list are very crowded and are associated with similar temporal contexts, whereas the last items are more separated in time and are associated with more discriminable temporal contexts. Neath and Crowder's (1990) results showed that recall performance increased as a function of the temporal discriminability of the items.

K. Guérard, katherine.guerard.1@ulaval.ca 
Only a very small number of studies have manipulated the ISIs for spatial information, and it is still not clear whether time also produces distinctiveness effects in the spatial domain. For example, Parmentier, King, and Dennis (2006) asked their participants to recall the order in which spatially located sounds had been presented (cf. Parmentier \& Jones, 2000). The sounds were separated by random intervals of different length. They found that memory for spatial locations did not benefit from temporal distinctiveness (see also Lewandowsky et al., 2006). In another study, however, Parmentier, Maybery, and Jones (2004; see also Parmentier, Andrés, Elford, \& Jones, 2006) introduced temporal grouping in recall of auditory tones played from different spatial locations. Unlike in the previously described experiment, this manipulation was a single temporal gap to divide the list in two groups. A recall advantage reminiscent of temporal grouping with verbal materials (e.g., Ryan, 1969) was observed, suggesting that time can be a relevant dimension for encoding items in spatial serial recall. One goal of the present study was to examine whether time could produce distinctiveness effects in the spatial domain, by adopting the procedure employed by Neath and Crowder (1990) with increasing and decreasing schedules of presentation.

Several studies in which distinctiveness effects have been investigated have manipulated the perceptual characteristics of the to-be-remembered information. The classic procedure consists of isolating one item in a list of verbal items (e.g., Cimbalo, Capria, Neider, \& Wilkins, 1977; Cunningham, Marmie, \& Healy, 1998; Huang, Ballering, \& Nikl, 1974; Kelley \& Nairne, 2001; Kroll, 1972; Smith $\&$ Stearns, 1949). For example, Kelley and Nairne presented a series of words to participants, who were asked to recall the list items in the same order as that in which they had been presented. One of the six items on the list appeared in a different font size from the other items. Kelley and Nairne showed that this item was recalled better than the same item in a homogeneous list in which all the items were the same size. This effect is known as the isolation effect or the von Restorff effect (see, e.g., von Restorff, 1933). Importantly, Kelley and Nairne showed that isolation had a beneficial effect on memory regardless of whether the isolated item was smaller or larger than the remaining items of the list, ruling out the interpretation that a larger item is somehow easier to process.

To our knowledge, only one study has demonstrated an isolation effect using spatial materials. Adopting a method used by Jones, Farrand, Stuart, and Morris (1995), Guérard, Hughes, and Tremblay (2008) presented participants with sequences of dots in different locations. One of the dots was presented in red, whereas the remaining dots were presented in black. After presentation, all the dots reappeared simultaneously in black on the computer screen, and the participants had to click on the dots in their order of appearance. Just as with verbal materials, performance for the red isolate was enhanced, as compared with a nonisolated item, suggesting that the same memory principles apply to the processing of verbal and spatial information.
Perceptual isolation has been largely employed in order to study distinctiveness effects. This procedure, however, does not capture the serial nature of order memory. Indeed, the critical manipulation focuses on a single item within the whole list. Consequently, it is difficult to know whether the memory processes responsible for the isolation effect are also used for the retention of the whole list or whether they are at play only for the retention of the single isolated item. In order to verify this idea in the present experiments, item discriminability was varied throughout the whole list. The procedure used by Neath and Crowder (1990) was extended to the perceptual dimension, so that the items' perceptual discriminability increased or decreased across serial positions.

Although most models based on distinctiveness have not been applied to memory for spatial information, there is nothing about the models that would either preclude spatial distinctiveness effects or make them different from those observed with verbal information. Indeed, one such model based on the principle of feature overwriting has successfully been applied to the processing of spatial information (see Oberauer \& Kliegl, 2006). According to some distinctiveness models of memory, items that are presented for recall are encoded along several dimensions (e.g., Brown, Neath, \& Chater, 2007; Brown, Preece, \& Hulme, 2000). For example, items can be encoded along perceptual dimensions, such as color or shape, and along a temporal dimension, on which each item is associated to a context representing its order in the sequence. At the time of recall, participants choose the dimension that provides the more useful retrieval cues (see Geiger \& Lewandowsky, 2008; Lewandowsky, Nimmo, \& Brown, 2008). Adjacent items on the selected dimension-whether it is perceptual or temporal - share similar features and compete during recall. When an item is distinct from its near neighbors, it can be retrieved more easily, because its competitors are farther away along that dimension. According to this view, performance should vary according to the discriminability of an item, relative to its neighbors on a given dimension.

The objective of the present series of experiments was to extend distinctiveness effects to the spatial domain by manipulating temporal and perceptual characteristics over the whole serial position curve in a spatial order reconstruction task. Spatial order reconstruction, such as that employed by Jones et al. (1995), was used in preference to Corsi blocks in order to minimize verbal recoding, a strategy that might be adopted when a set of locations is visible throughout the whole experiment (see, e.g., Parmentier, Elford, \& Maybery, 2005). Because the distinctiveness effect is one of order memory, however, similar results would be expected regardless of whether spatial items remain visible or not to participants. In Experiment 1, therefore, a method similar to that in Guérard et al. (2008) was used but the schedule of presentation was manipulated in order to examine the effects of temporal distinctiveness on the processing of spatial information (see Neath \& Crowder, 1990). In Experiment 2, we also used the dot task but examined whether the effects observed with the 
temporal manipulation could be extended to other perceptual dimensions.

\section{EXPERIMENT 1A}

Neath and Crowder $(1990,1996)$ demonstrated that when the time interval between items increases across list items, so that the first items are very crowded and the last ones are separated by longer intervals, primacy decreases and recency increases; in contrast, when the time interval between each item decreases across list items, primacy increases and recency decreases. The purpose of Experiment $1 \mathrm{~A}$ was to see whether increasing and decreasing schedules of presentation would affect memory, when assessed by a spatial reconstruction of an order task. In the increasing condition, ISIs increased across serial positions, so that they were shorter for the first serial positions than for the last serial positions. In the decreasing condition, the same intervals were used, but in the reverse order. If temporal distinctiveness affects memory for spatial information, the results should be similar to those observed with verbal information (see, e.g., Neath \& Crowder, 1990). Experiment 1B employed a similar procedure, but with random ISIs.

\section{Method}

Participants. Twenty students from Université Laval volunteered to take part in the experiment in exchange for a small honorarium. All reported normal or corrected-to-normal vision.

Apparatus and Materials. The stimuli were sequences of seven black dots, 50 pixels in diameter, presented in different locations on the screen within a window of $450 \times 400$ pixels. The items' coordinates were determined randomly for each sequence. In the increasing condition, the ISIs increased as a function of serial position and corresponded to $0,250,500,1,000,2,000$, and 4,000 msec, respectively (see Figure 1). In the decreasing condition, the same ISIs were used, but in the reverse order, so that the duration of the ISIs decreased across serial positions. There was also a control condition in which all ISIs were set at $1,000 \mathrm{msec}$. In all the conditions, each dot remained on the screen for $1,000 \mathrm{msec}$.

Design. The experiment had two repeated measures factors: schedule of presentation (three levels: control, increasing, and decreasing) and serial position (seven levels: 1-7). There were 45 trials (15 in each condition), which were presented in a different random order for each participant.

Procedure. The participants were tested individually. On each trial, seven items were presented successively at different locations on the screen. Each dot remained on the screen for 1,000 msec. A 1,000 -msec blank interval followed the last dot, after which all the dots reappeared simultaneously on the screen. The participants were required to click on the dots in the same order as that in which they had been presented. Each time a dot was selected, it turned green. The experimental session lasted approximately $30 \mathrm{~min}$.

\section{Results and Discussion}

A response was considered correct when an item was recalled in the same serial position as that in which it had been presented. As is shown in Figure 2, recall performance was better for the first serial positions in the decreasing condition, whereas it was better for the last serial position in the increasing condition, replicating the pattern observed by Neath and Crowder (1990, 1996). A 3 (schedule of presentation) $\times 7$ (serial position) repeated measures ANOVA was performed on the proportion correct. In all analyses, the .05 level of significance was adopted, and the Greenhouse-Geisser correction was applied when sphericity was violated. The analysis revealed that the main effect of schedule of presentation was not significant $(F<1)$ but that the main effect of serial position was significant $\left[F(6,114)=16.10, M S_{\mathrm{e}}=\right.$ $\left.0.05, \eta_{\mathrm{p}}^{2}=.459\right]$. Importantly, the interaction between schedule of presentation and serial position was significant $\left[F(12,228)=5.64, M S_{\mathrm{e}}=0.01, \eta_{\mathrm{p}}^{2}=.229\right]$, suggest-

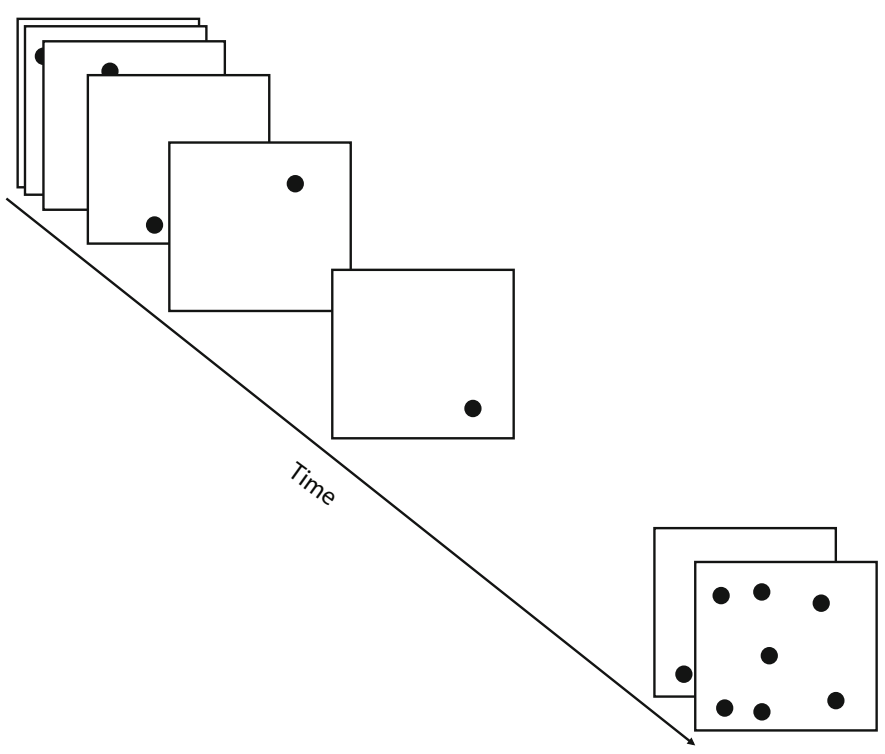

Figure 1. Schematic representation of the task in the increasing condition in Experiment 1A. 


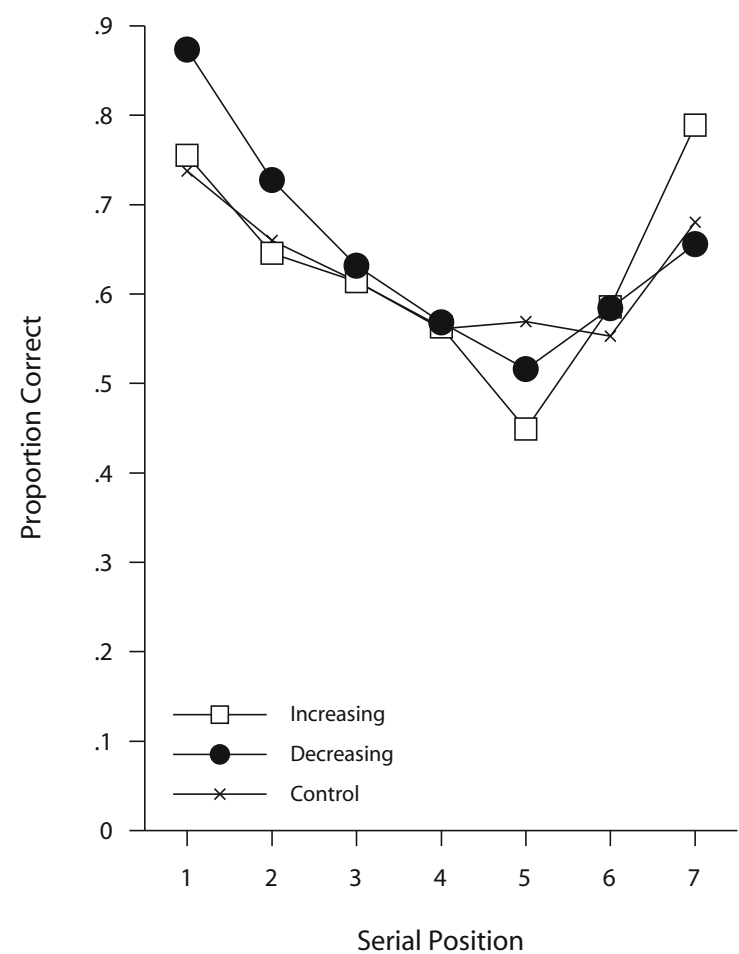

Figure 2. Proportion correct as a function of serial position for the control, increasing, and decreasing conditions in Experiment 1A.

ing that performance for an item increases as the temporal distance from its neighbors increases. Interestingly, however, recall performance for the crowded portion of the list in the increasing and decreasing conditions appeared to be equivalent to that in the control lists (see Figure 2). One possibility is that the items that were more crowded appeared to be less distinctive than those presented in the control condition ( $1,000 \mathrm{on} / 1,000$ off $)$ but that this lower discriminability significantly altered performance only when contrasted against more spaced items (such as those separated by 2 or $4 \mathrm{sec}$ ).

In order to investigate further the effect of discriminability on the primacy and recency effects, we used an absolute measure of primacy and recency (see also Nicholls \& Jones, 2002; Tremblay, Parmentier, Guérard, Nicholls, $\&$ Jones, 2006); that is, we compared the proportion correct for the first item and last item in the increasing and decreasing conditions. These data were analyzed within a 2 (schedule of presentation: increasing or decreasing) $\times 2$ (position: primacy or recency) repeated measures ANOVA that showed that the main effects of schedule of presentation $(F<1)$ and of position $[F(1,19)=$ $\left.1.82, M S_{\mathrm{e}}=0.02, \eta_{\mathrm{p}}^{2}=.09\right]$ were not significant. The interaction between schedule of presentation and position was significant $\left[F(1,19)=24.33, M S_{\mathrm{e}}=0.02, \eta_{\mathrm{p}}^{2}=\right.$ $.56]$, confirming that the first item was recalled better in the decreasing condition than in the increasing condition, whereas the final item was recalled better in the increasing condition than in the decreasing condition.

\section{EXPERIMENT 1B}

Experiment 1A showed a temporal distinctiveness effect in the spatial domain, using increasing and decreasing schedules of presentation. Some studies, however, have shown that there is no temporal distinctiveness effect when the duration of the intervals varies randomly (e.g., Lewandowsky et al., 2006; Nimmo \& Lewandowsky, 2005, 2006; Parmentier, King, \& Dennis, 2006), instead of following a predictable schedule, such as the increasing and decreasing schedules of presentation used in Experiment 1A. This null effect is consistent with the idea that temporal effects may be due to selective rehearsal strategies, rather than to the use of temporal coding per se. This hypothesis was tested in Experiment 1B within a spatial reconstruction task: For a set of sequences, the duration of all ISIs was determined randomly (completely random trials). In order to measure the effect of randomizing the ISI durations, three critical conditions were added to the completely random trials, in which all ISIs were determined randomly, except for those before and after the presentation of the fourth item. These two ISIs were of equal length, and their duration was $400,1,000$, or $1,600 \mathrm{msec}$. Recall performance for the fourth item was assessed in these three conditions, as well as in the completely random condition. Trials in the four conditions were presented randomly, so that the participants would not notice the manipulation in the 400-, $1,000-$, and 1,600-msec conditions. If temporal distinctiveness effects disappear when the duration of the ISIs is unpredictable, performance should be equivalent in the four conditions. If temporal distinctiveness affects memory for spatial information even with random ISIs, recall performance for the fourth item should increase as a function of its temporal distance from its neighborsthat is, from the 400 - to the 1,600 -msec condition.

\section{Method}

Participants. Twenty students from Memorial University of Newfoundland volunteered to take part in the experiment in exchange for a small honorarium. All reported normal or correctedto-normal vision.

Apparatus and Materials. The stimuli consisted of sequences of seven blue dots 50 pixels in diameter, presented in different locations on the screen. For each participant, 45 sequences were constructed from the random ordering of the same seven locations. The seven locations were selected from a grid of $10 \times 10$ cells, with the restriction that no dot appeared in a cell adjacent to the cell of another dot. The dimension of each cell was $50 \times 50$ pixels. No part of the grid was visible. A different set of locations was selected for each participant.

In the 400 condition, the intervals inserted before and after the fourth item lasted $400 \mathrm{msec}$. The other intervals were set at 200 , $800,1,200$, and $1,600 \mathrm{msec}$ and were randomly assigned to the four remaining ISIs $(1-2,2-3,5-6,6-7)$. In the 1,000 and 1,600 conditions, the fourth item was surrounded by intervals of 1,000 and $1,600 \mathrm{msec}$, respectively. The other intervals were set at 200, 400, 800 , and $1,200 \mathrm{msec}$ in the 1,000 condition and at 200,200,400, and $600 \mathrm{msec}$ in the 1,600 condition. In the random condition, the 
intervals were set at 200,400,600, 800,1,000, and 1,600 msec and were randomly assigned to the six ISIs.

Design. The experiment had one repeated measures factor: interval (four levels; 400, 1,000, 1,600, or random). There were 10 trials in each condition, except in the random condition, in which there were 20 trials. The trials in all the conditions were presented in a different random order for each participant.

Procedure. The procedure was the same as that in Experiment 1A, except that each dot remained on the screen for $1,000 \mathrm{msec}$, followed by an ISI determined for that trial and position.

\section{Results}

The key data concern recall of the fourth item. As is shown in Figure 3, accuracy was higher in the 1,600 condition than in the other three conditions. A 4 (interval) repeated measures ANOVA was performed on proportion correct at serial position four. The analysis revealed that the main effect of interval was significant $[F(3,72)=$ 3.57, $\left.M S_{\mathrm{e}}=0.02, \eta_{\mathrm{p}}^{2}=.130\right]$. Paired samples $t$ tests showed that accuracy was higher in the 1,600 condition than in the 400 condition $[t(22)=2.48, p<.05], 1,000$ condition $[t(22)=2.59, p<.05]$, and random condition $[t(22)=2.44, p<.05]$. No other comparison was significant.

In order to examine the effect of temporally isolating an item on recall performance for the whole serial position curve, a 4 (interval) $\times 7$ (serial position) repeated measures ANOVA was carried out on proportion correct. The analysis indicated that the main effect of serial position was significant $\left[F(6,144)=37.24, M S_{\mathrm{e}}=0.04\right.$, $\left.\eta_{\mathrm{p}}^{2}=.608\right]$. Neither the main effect of interval $[F(3,72)=$ 2.63, $\left.M S_{\mathrm{e}}=0.05, \eta_{\mathrm{p}}^{2}=.099\right]$ nor the interaction between interval and serial position was significant $[F(18,432)=$ $\left.1.45, M S_{\mathrm{e}}=0.02, \eta_{\mathrm{p}}^{2}=.057\right]$, indicating that the duration of the intervals surrounding the fourth item did not affect overall performance.

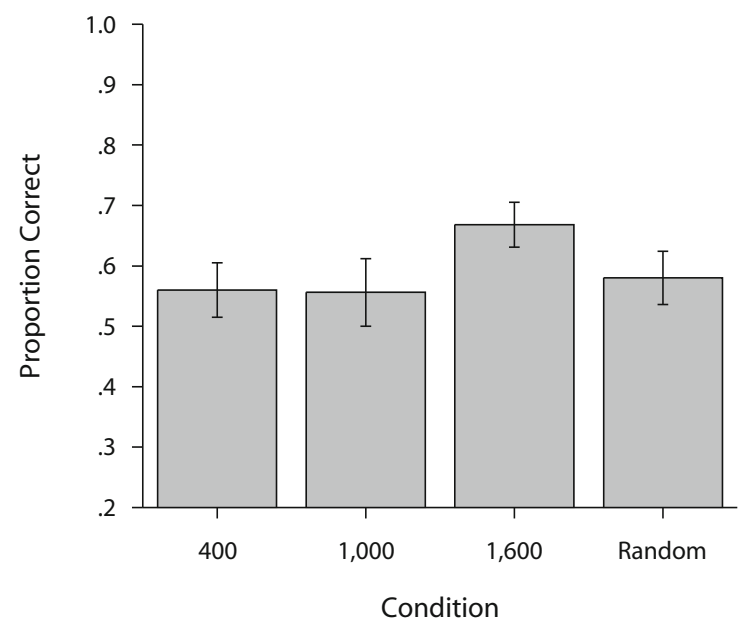

Figure 3. Proportion correct at the fourth serial position for the 400, 1,000, 1,600, and random conditions in Experiment $1 \mathrm{~B}$. Error bars represent standard errors of the means.

\section{Discussion}

Our results showed that increasing the duration of the intervals isolating an item from its neighbors enhanced recall performance for that item (see, e.g., Glenberg \& Swanson, 1986). These findings are consistent with those of Parmentier et al. (2004; see also Parmentier, Andrés, et al., 2006) but may appear to be in contrast with those reported in other studies showing that, in particular circumstances, temporal distinctiveness has no effect on memory (Lewandowsky et al., 2006; Nimmo \& Lewandowsky, 2005, 2006; Parmentier, King, \& Dennis, 2006). In Experiment 1B, despite the unpredictability of the duration of the temporal gaps, the middle item of the list still benefited from temporal isolation when it was surrounded by intervals of $1,600 \mathrm{msec}$. In this condition, however, the intervals surrounding the middle item were almost three times longer than the next largest interval $(600 \mathrm{msec})$ presented in the same series. This high ratio between the intervals surrounding the isolated item and the other intervals may be essential in order to make the item "stand out" in a sequence characterized by random intervals and to induce participants to rely on a temporal code (see Geiger \& Lewandowsky, 2008), which is necessary in order to produce a temporal distinctiveness effect. Indeed, in the previous studies - as well as in the 1,000msec condition of the present experiment - the ratio between the critical interval and the longest interval in the same sequence was much lower: Although intervals up to $4 \mathrm{sec}$ were used, they were presented in combination with intervals of 3 and $2 \mathrm{sec}$ within the same trial (Nimmo \& Lewandowsky, 2005, 2006). Moreover, different procedures that increase reliance on a temporal code, such as a running memory task (Geiger \& Lewandowsky, 2008), free recall (Brown et al., 2006), and unconstrained reconstruction (Lewandowsky et al., 2008), have proven to be sensitive to temporal discriminability. It seems, therefore, that, as is the case with verbal material, participants can use the temporal dimension during the retrieval of spatial information when such dimension provides useful cues for recall.

\section{EXPERIMENT 2}

Experiment 1A demonstrated that temporal schedules of presentation affected memory for spatial information just like memory for verbal information (see, e.g., Neath \& Crowder, 1990, 1996). In Experiment 2, we examined whether this effect also could be generalized to dimensions other than time. In the increasing condition, darkness or "squareness" increased as a function of serial position, so that the value of item $n$ was two times higher than that of the preceding item on a given dimension. For example, for the dimension of darkness, the second item of the list was twice as dark as the first item, the third item was twice as dark as the second one, and so forth (see Figure 4). In the increasing condition, the first items of the sequence were characterized by lightness values that were more difficult to discriminate from each other than those characterizing the last items of the sequence. In the decreasing condition, 

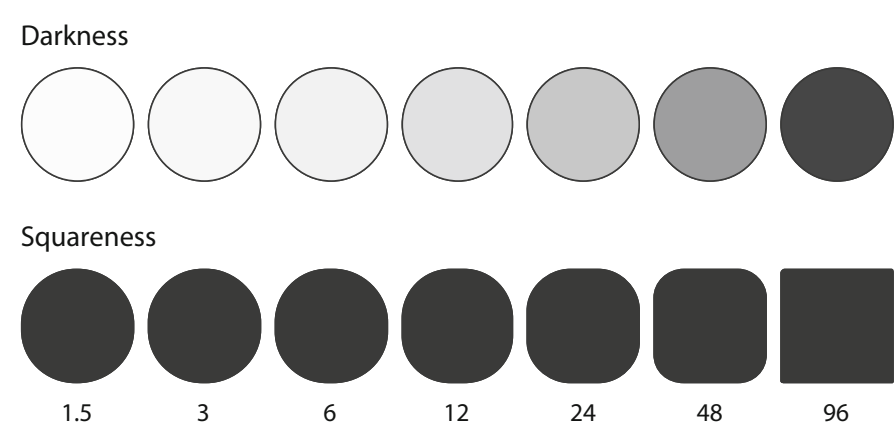

Figure 4. Stimuli used for dimensions of darkness (top) and squareness (bottom) in Experiment 2. They are presented in increasing order. Their value on each dimension is indicated at the bottom.

the list was presented in the reverse order, so that the first items were more discriminable from each other than the last items of the list. If all items are encoded along a perceptual dimension and item discriminability along that dimension affects memory, the increasing condition should yield a stronger recency effect but a weaker primacy effect than should the decreasing condition, just as was observed for the temporal dimension in Experiment 1A.

\section{Method}

Participants. Forty students from Université Laval volunteered to take part in the experiment in exchange for a small honorarium. All reported having normal or corrected-to-normal vision.

Apparatus and Materials. As in Experiment 1A, the stimuli consisted of sequences of seven items presented in different locations on the screen. The stimuli were created using Corel Draw 10.0. In the darkness condition, items were circles 50 pixels in diameter, for which the darkness value was manipulated. In the increasing condition, the successive dots' darkness values corresponded to 1.5 , $3,6,12,24,48$, and 96 , respectively (with 0 being white and 100 being black). In the decreasing condition, this order was reversed, so that the first item had a value of 96 , the second one had a value of 48 , and so forth. In the squareness condition, all the stimuli were presented in black. The shape of the stimuli was varied in the same way as that for darkness: Angle squareness was manipulated from 1.5 to 96 (with 0 being completely round and 100 being completely squared). For each of the darkness and squareness conditions, there was also a control condition in which all the items corresponded to the middle value (12). This value was also used for representing all the items simultaneously for recall in all the conditions. The stimuli in the increasing condition for the squareness and darkness groups are illustrated in Figure 4.

Design. The experiment had one between-subjects factor, dimension (two levels: darkness and squareness), and two repeated measures factors, discriminability (three levels: control, increasing, and decreasing), and serial position (seven levels: $1-7$ ). There were 20 participants in the darkness condition and 20 participants in the squareness condition. There were 60 trials ( 20 in each condition) that were presented in a different random order for each participant.

Procedure. On each trial, seven items were presented successively at different locations on the screen. Each dot remained on the screen for $1,000 \mathrm{msec}(1,000 \mathrm{on} / 0 \mathrm{off})$. The procedure in the increasing condition for the darkness group is illustrated in Figure 5.

\section{Results and Discussion}

As is shown in Figure 6, recency was greater in the increasing condition, whereas primacy was greater in the decreasing condition, no matter which dimension was manipulated. A 2 (dimension) $\times 3$ (discriminability) $\times 7$ (serial position) mixed ANOVA revealed that neither the main effect of discriminability $\left[F(2,76)=1.49, M S_{\mathrm{e}}=0.02\right.$, $\left.\eta_{\mathrm{p}}^{2}=.04\right]$ nor the main effect of dimension $(F<1)$ was significant. The main effect of serial position was significant $\left[F(6,228)=86.22, M S_{\mathrm{e}}=0.04, \eta_{\mathrm{p}}^{2}=.69\right]$. Importantly, the interaction between discriminability and serial position was significant $\left[F(12,456)=7.12, M S_{\mathrm{e}}=0.01, \eta_{\mathrm{p}}^{2}=.16\right]$, suggesting that the shape of the serial position curve was modulated by the relative distinction between successive items. No other interactions were significant.

A 2 (dimension) $\times 2$ (discriminability: increasing or decreasing) $\times 2$ (position: primacy or recency) mixed ANOVA was also carried out on the absolute measure of primacy and recency. The analysis revealed that the main effects of domain, discriminability, and position were not significant $\left(F_{\mathrm{S}}<1\right)$. The interaction between discriminability and position was significant $[F(1,38)=$ $15.32, M S_{\mathrm{e}}=0.01, \eta_{\mathrm{p}}^{2}=.29$ ], suggesting that primacy and recency improved, respectively, when the first and last items' physical characteristics were easier to discriminate from their neighbor. No other interactions were significant. This pattern suggests that item discriminability influences the shape of the serial position curve in spatial order reconstruction. The interaction between the increasing and decreasing conditions is very similar to that observed in Experiment 1A (see also Neath \& Crowder, 1990), in which the duration of the interval separating successive items in a list of words presented visually on the computer screen was manipulated.

\section{GENERAL DISCUSSION}

The objective of the present study was to examine whether serial memory for spatial information is influenced by the discriminability of to-be-remembered items, whether discriminability is induced by manipulating the physical or temporal characteristics of a whole sequence. The results indicated that performance at primacy and recency portions of the list improved, respectively, when the first and last items were more distinct from each other, no matter whether we manipulated the interval of time 


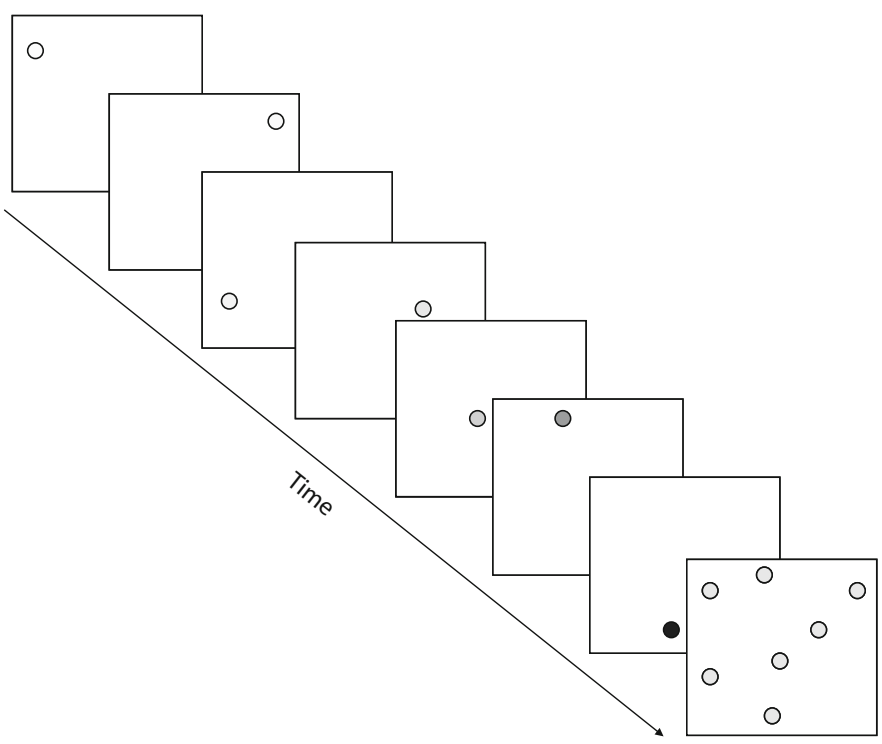

Figure 5. Schematic representation of the task in the increasing condition for the darkness group in Experiment 2.

inserted between successive items (Experiment 1A) or a perceptual dimension such as darkness or squareness (Experiment 2). This pattern of results is very similar to that reported by studies that varied the schedule presentation with verbal information (see, e.g., Neath \& Crowder, 1990, 1996; Rönnberg, 1980; Welte \& Laughery, 1971) and adds to the large body of evidence showing that item discriminability modulates memory performance (see, e.g., Kelley \& Nairne, 2001). It also shows that perceptual and temporal distinctiveness effects occur in the spatial domain and that both types of manipulation produce very similar effects.
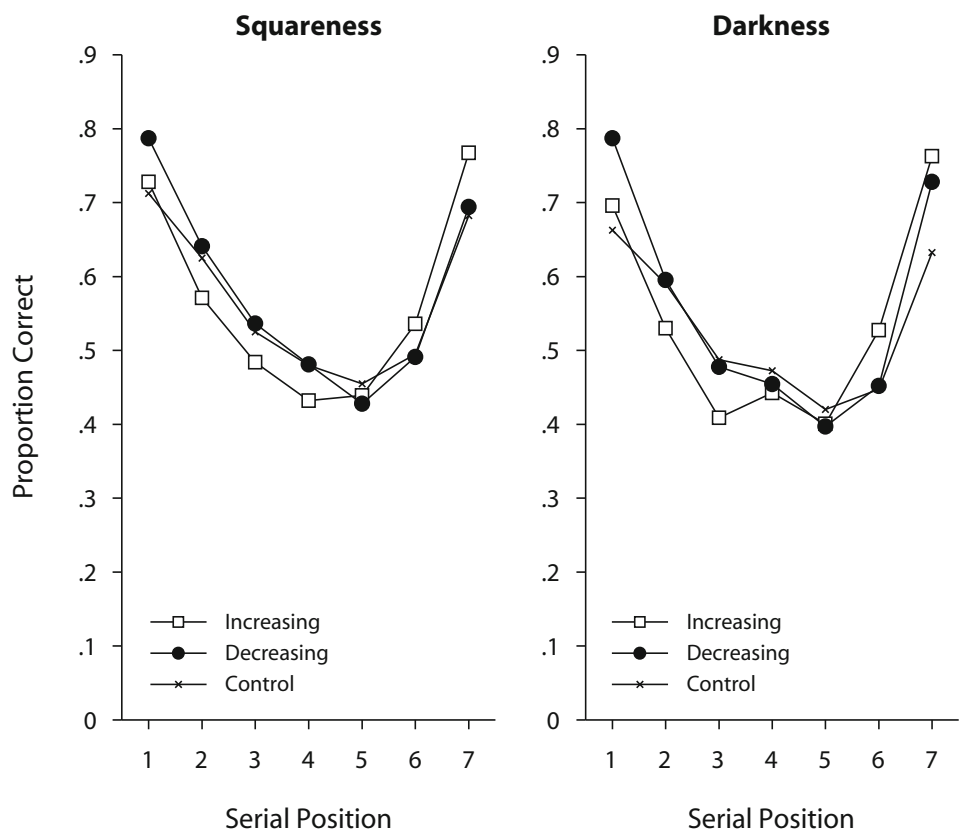

Figure 6. Proportion correct as a function of serial position for the control, increasing, and decreasing conditions for the squareness (left) and darkness (right) dimensions in Experiment 2. 


\section{The Psychological Process That Mediates the Effect of Distinctiveness}

Hunt and Lamb (2001) suggested that distinctiveness effects occur when the characteristics that distinguish an item from other items are processed (i.e., distinctive processing) and contrast with the relational processing given to a whole list. Relational processing allows grouping of list items around a common characteristic and the definition of a more precise search set during recall. SIMPLE (Brown et al., 2007; Neath \& Brown, 2006) provides another explanation for distinctiveness effects. According to Brown et al. (2007), items are encoded along several dimensions, such as their time of presentation and their perceptual characteristics. The closer items are to each other on a given dimension, the less discriminable they are and the more difficult they are to recall. The distinctive/ relational view is not completely at odds with the principles underlying SIMPLE. On the one hand, Brown et al. (2007) suggested that all items are encoded along common dimensions. This idea can be compared with relational processing, since it allows comparing all items on the basis of a common characteristic (e.g., color). On the other hand, the spacing of items along these dimensions is analogous to distinctive processing: More spaced items are represented by more distinctive memory traces. According to SIMPLE, however, distinct items do not benefit from a particular type of processing that the other items on the list do not enjoy. Indeed, all memory traces differ only according to their value along a given dimension (which can be defined quantitatively), not on their level of elaboration or on the type of elaboration (distinctive vs. relational). It is the difference between an item's value and that of its neighbors that determines the level of recall.

According to SIMPLE (Brown et al., 2007), the same processes are responsible for producing the interaction between the increasing and decreasing schedules of presentation and for the typical isolation effect observed when a single item from a list is isolated using a different color (see, e.g., Kelley \& Nairne, 2001). Indeed, in a typical isolation effect, the isolated item would be recalled better because it tends to be further away from its neighbors along the manipulated dimension (see, e.g., Brown et al., 2007). In that case, the isolated item would stand alone and be separated from the remaining items, all of which would be crowded around the same value. The black (or squared) item in the present experiment could be compared with an isolated item, the only difference being that the remaining items would be more scattered than those in the typical isolation effect. If the distinctiveness effect occurs as a result of a comparison between a given item and its immediate neighbors - which is predicted by a local distinctiveness model (see Neath, Brown, McCormack, Chater, \& Freeman, 2006) - the advantage of the first black item, as compared with the second gray item - should be equivalent regardless of whether Items 3-7 share the same value or decrease along the darkness dimension.

A comparison of Experiments 1A and 2 shows that manipulating the temporal or physical characteristics of a list yields similar distinctiveness effects, which suggests that items in a spatial memory task can be encoded along sev- eral dimensions and that these dimensions are functionally similar. Manipulating a given characteristic throughout a list makes that characteristic relevant for retrieval, since it provides an additional cue that allows one to differentiate among the list items. During recall, then, participants may decide to orient their attention toward that characteristic, which leads to the observed distinctiveness effects (see, e.g., Geiger \& Lewandowsky, 2008). Indeed, items that share similar darkness values are closer on the dimension of darkness and are more difficult to recall because they are less discriminable from each other. The same logic applies to other dimensions, such as time. According to some distinctiveness models of memory, items that are presented for recall are associated with a context representing their order in the sequence (e.g., Brown et al., 2007; Brown et al., 2000; Burgess \& Hitch, 1999). This context may take the form of oscillators representing the position of the to-beremembered items in time. According to this idea, items that are closer in time are related to more similar contexts than are items presented further away. The context signal is then used as a retrieval cue to recall the item with which it was associated. If the context signal associated with an item is distinct from that of its neighbors, the probability of correctly recalling this item increases, because the tendency to confuse this item with its neighbors is reduced. The idea that recall performance depends on item discriminability along a given dimension has also been used to explain classical memory phenomena, such as the acoustic similarity effect (see Surprenant, Neath, \& Brown, 2006).

Most distinctiveness models were developed to account for performance in verbal memory tasks (e.g., Brown et al., 2007; Brown et al., 2000; Nairne, 1990; see, however, Oberauer \& Kliegl, 2006). These models, however, do not need to be specific to the verbal domain and have already been extended to fit performance on absolute identification tasks carried out with visual material (see Neath et al., 2006). Our results suggest that such models can also be used to explain the processing of spatial information. More generally, our results are consistent with unitary views of memory that do not postulate the existence of separate components responsible for the processing of different types of information, at least when order memory is involved (e.g., Cowan, 1999; Jones, Hughes, $\&$ Macken, 2006). An example of such a unitary view is the perceptual-gestural framework (Jones et al., 2006), according to which the same processes, such as perceptual organization and the planning of action, underlie the retention of information, regardless of the type of information being processed. The extension of the distinctiveness effects to the spatial domain adds to the large body of evidence showing that the processing of verbal information and the processing of spatial information are functionally equivalent (see, e.g., Avons, 1998; Jones et al., 1995; Smyth \& Scholey, 1996).

\section{AUTHOR NOTE}

This work was supported by NSERC grants to I.N., A.M.S., and S.T. Thanks are due to Jean Saint-Aubin for his helpful comments and to Justine Tremblay and Michel-Pierre Coll for assistance in running the experiments. Correspondence can be addressed to K. Guérard, École de 
Psychologie, Université Laval, Québec, QC, G1V 0A6 Canada (e-mail: katherine.guerard.1@ulaval.ca).

\section{REFERENCES}

Avons, S. E. (1998). Serial report and item recognition of novel visual patterns. British Journal of Psychology, 89, 285-308.

Bireta, T. J., Surprenant, A. M., \& Neath, I. (2008). Age-related differences in the von Restorff isolation effect. Quarterly Journal of Experimental Psychology, 61, 345-352.

Brown, G. D. A., Morin, C., \& Lewandowsky, S. (2006). Evidence for time-based models of free recall. Psychonomic Bulletin \& Review, 13, 717-723.

Brown, G. D. A., Neath, I., \& Chater, N. (2007). A temporal ratio model of memory. Psychological Review, 114, 539-576.

Brown, G. D. A., Preece, T., \& Hulme, C. (2000). Oscillator-based memory for serial order. Psychological Review, 107, 127-181.

Burgess, N., \& Hitch, G. (1999). Memory for serial order: A network model of the phonological loop and its timing. Psychological Review, 106, 551-581.

Cimbalo, R. S., Capria, R. A., Neider, L. L., \& Wilkins, M. A. C. (1977). Isolation effect: Overall list facilitation in short-term memory. Acta Psychologica, 41, 419-432.

CowAN, N. (1999). An embedded process model of working memory. In A. Miyake \& P. Shah (Eds.), Models of working memory (pp. 62-101). New York: Cambridge University Press.

Cunningham, T. F., Marmie, W. R., \& Healy, A. F. (1998). The role of item distinctiveness in short-term recall of order information. Memory \& Cognition, 26, 463-476.

Geiger, S. M., \& Lewandowsky, S. (2008). Temporal isolation does not facilitate forward serial recall—or does it? Memory \& Cognition, 36, 957-967.

Geraci, L., McDaniel, M. A., Manzano, I., \& Roediger, H. L., III (2009). The influence of age on memory for distinctive events. Memory \& Cognition, 37, 175-180.

GlenberG, A. M., \& Swanson, N. C. (1986). A temporal distinctiveness theory of recency and modality effects. Journal of Experimental Psychology: Learning, Memory, \& Cognition, 12, 3-15.

Guérard, K., Hughes, R. W., \& Tremblay, S. (2008). An isolation effect in serial memory for spatial information. Quarterly Journal of Experimental Psychology, 61, 752-762.

HuANG, I. N., Ballering, L., \& NiKL, L. D. (1974). Isolation effect in immediate and delayed free recall. Journal of General Psychology, 91, 81-85.

Huang, I. N., \& Wille, C. (1979). The von Restorff isolation effect in free recall. Journal of General Psychology, 101, 27-34.

Hunt, R. R., \& LAMB, C. A. (2001). What causes the isolation effect? Journal of Experimental Psychology: Learning, Memory, \& Cognition, 27, 1359-1366.

Jones, D. M., Farrand, P., Stuart, G., \& Morris, N. (1995). Functional equivalence of verbal and spatial information in serial shortterm memory. Journal of Experimental Psychology: Learning, Memory, \& Cognition, 21, 1008-1018.

Jones, D. M., Hughes, R. W., \& Macken, W. J. (2006). Perceptual organization masquerading as phonological storage: Further support for a perceptual-gestural view of short-term memory. Journal of Memory \& Language, 54, 265-281.

KelLey, M. R., \& NaIRne, J. S. (2001). Von Restorff revisited: Isolation, generation, and memory for order. Journal of Experimental Psychology: Learning, Memory, \& Cognition, 27, 54-66.

KroLL, N. E. (1972). The von Restorff effect as a function of method of isolation. Psychonomic Science, 26, 333-334.

Lewandowsky, S., Brown, G. D. A., Wright, T., \& Nimmo, L. M. (2006). Timeless memory: Evidence against temporal distinctiveness models of short-term memory for serial order. Journal of Memory \& Language, 54, 20-38.

Lewandowsky, S., Nimmo, L. M., \& Brown, G. D. A. (2008). When temporal isolation benefits memory for serial order. Journal of Memory \& Language, 58, 415-428.

Murdock, B. B., Jr. (1960). The distinctiveness of stimuli. Psychological Review, 67, 16-31.

NAIRNE, J. S. (1990). A feature model of immediate memory. Memory \& Cognition, 18, 251-269.
NeAth, I., \& Brown, G. D. A. (2006). SIMPLE: Further applications of a local distinctiveness model of memory. In B. H. Ross (Ed.), The psychology of learning and motivation (Vol. 46, pp. 201-243). San Diego: Academic Press.

Neath, I., \& Brown, G. D. A. (2007). Making distinctiveness models of memory distinct. In J. S. Nairne (Ed.), The foundations of remembering: Essays in honor of Henry L. Roediger III (pp. 125-140). New York: Psychology Press.

Neath, I., Brown, G. D. A., McCormack, T., Chater, N., \& FreeMAN, R. (2006). Distinctiveness models of memory and absolute identification: Evidence for local, not global, effects. Quarterly Journal of Experimental Psychology, 59, 121-135.

Neath, I., \& Crowder, R. G. (1990). Schedules of presentation and temporal distinctiveness in human memory. Journal of Experimental Psychology: Learning, Memory, \& Cognition, 16, 316-327.

Neath, I., \& Crowder, R. G. (1996). Distinctiveness and very shortterm serial position effects. Memory, 4, 225-242.

Nicholls, A. P., \& Jones, D. M. (2002). Capturing the suffix: Cognitive streaming in immediate serial recall. Journal of Experimental Psychology: Learning, Memory, \& Cognition, 28, 12-28.

Nimmo, L. M., \& LewandowsKy, S. (2005). From brief gaps to very long pauses: Temporal isolation does not benefit serial recall. Psychonomic Bulletin \& Review, 12, 999-1004.

Nimmo, L. M., \& LeWANDOWSKY, S. (2006). Distinctiveness revisited: Unpredictable temporal isolation does not benefit short-term serial recall of heard or seen events. Memory \& Cognition, 34, 1368-1375.

ObERAUER, K., \& KLIEGL, R. (2006). A formal model of capacity limits in working memory. Journal of Memory \& Language, 55, 601-626.

Parmentier, F. B. R., Andrés, P., Elford, G., \& Jones, D. M. (2006). Organization of visuo-spatial serial memory: Interaction of temporal order with spatial and temporal grouping. Psychological Research, 70, 200-217.

Parmentier, F. B. R., Elford, G., \& Maybery, M. T. (2005). Transitional information in spatial serial memory: Path characteristics affect recall performance. Journal of Experimental Psychology: Learning, Memory, \& Cognition, 31, 412-427.

Parmentier, F. B. R., \& Jones, D. M. (2000). Functional characteristics of auditory temporal-spatial short-term memory: Evidence from serial order errors. Journal of Experimental Psychology: Learning, Memory, \& Cognition, 26, 222-238.

Parmentier, F. B. R., King, S., \& Dennis, I. (2006). Local temporal distinctiveness does not benefit auditory verbal and spatial serial recall. Psychonomic Bulletin \& Review, 13, 458-465.

Parmentier, F. B. R., Maybery, M. T., \& Jones, D. M. (2004). Temporal grouping in auditory spatial serial memory. Psychonomic Bulletin \& Review, 11, 501-507.

RöNNBERG, J. (1980). Predictability as a task demand in single-trial free recall. Scandinavian Journal of Psychology, 21, 83-95.

RYAN, J. (1969). Grouping and short-term memory: Different means and patterns of groups. Quarterly Journal of Experimental Psychology, 21, 137-147.

Smith, M. H., \& Stearns, E. G. (1949). The influence of isolation on the learning of surrounding materials. American Journal of Psychology, 62, 369-381.

Smyth, M. M., \& Scholey, K. A. (1996). Serial order in spatial immediate memory. Quarterly Journal of Experimental Psychology, 49A, 159-177.

Surprenant, A. M., Neath, I., \& Brown, G. D. A. (2006). Modeling age-related differences in immediate memory using SIMPLE. Journal of Memory \& Language, 55, 572-586.

Tremblay, S., Parmentier, F. B. R., Guérard, K., Nicholls, A., \& Jones, D. M. (2006). A spatial modality effect. Journal of Experimental Psychology: Learning, Memory, \& Cognition, 32, 1208-1215. doi:10.1037/0278-7393.32.5.1208

vON RESTORFF, H. (1933). Über die Wirkung von Bereichsbildungen im Spurenfeld [On the effect of spheres formations in the trace field]. Psychologische Forschung, 18, 299-342.

Welte, J. W., \& Laughery, K. R. (1971). Short-term memory: The effects of inter-item time distribution and recall procedure. Canadian Journal of Psychology, 25, 436-442.

(Manuscript received January 6, 2009; revision accepted for publication April 8, 2009.) 